\title{
"O Fim da Linha"? Etnografia da alimentação de idosos institucionalizados - reflexões a partir das contribuições metodológicas de Malinowski
}

\author{
"The Bottom Line"? Ethnography of eating in institutionalized elderly - \\ reflections from the methodological contributions of Malinowski
}

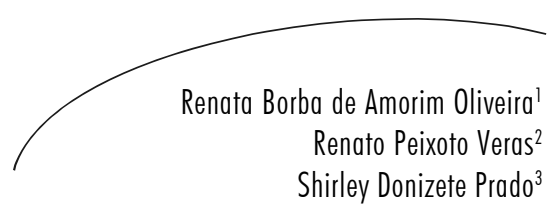

Este trabalho faz parte de uma investigação etnográfica que visa a apreender a significação da alimentação para idosos institucionalizados, a partir de um estudo qualitativo, tendo como base as reflexões de Bronislaw Malinowski. Foram aplicadas as técnicas de observação participante e entrevistas semiestruturadas com idosos de ambos os sexos, de idades entre 66 e 93 anos, residentes em duas Instituições de Longa Permanência para Idosos (ILPIs) localizadas no município do Rio de Janeiro, RJ, Brasil. Ao explorar as impressões do investigador, a observação de códigos internos, os padrões de comportamento, os fenômenos imponderáveis da vida real, a distribuição social das funções, e a organização social da comunidade em uma totalidade integrada, pudemos perceber que a rotina alimentar dentro da instituição é extremamente controlada e esvaziada de significado, por não levar em conta a identidade cultural e a individualidade dos idosos. Todavia, entendemos que uma mudança no paradigma alimentar através da ressignificação da alimentação poderia auxiliar no enriquecimento e melhor qualidade de vida dessa comunidade.

\section{Abstract}

This essay is part of an ethnographic research that seeks to grasp the meaning of alimentation for institutionalized elderly, from a qualitative research based on the reflections of Bronislaw Malinowski. We applied the techniques of participant observation and semi-structured interviews with elders of both sexes, aged between 66 and 93 years old, living in two institutions for the aged located in Rio de Janeiro, RJ, Brazil. Exploring the researcher's impressions,

\footnotetext{
Universidade do Estado do Rio de Janeiro

1 Faculdade de Ciências Médicas

2 Universidade Aberta da Terceira Idade

3 Instituto de Nutrição
}

Palavras-chave:

Alimentação. Alimentação

Coletiva. Serviços de

Alimentação.

Comportamento

Alimentar. Hábitos

Alimentares. Instituição

de Longa Permanência

para Idosos. Antropologia

Cultural. Qualidade de

Vida. Comportamento

Social. Pesquisa

Qualitativa. 
the observation of internal codes, standards of behavior, imponderable phenomena of real life, the social distribution of function, the organization of the community in an integrated whole, we find that the feeding routine within the institution is extremely controlled and deprived of meaning, as it does not take into account the cultural identity and individuality of the elderly. However, we believe that a paradigm shift in alimentation through the redefinition of eating could help enrich and better quality of life of this community.
Key words: Feeding. Collective Feeding. Food Services. Feeding Behavior. Food Habits. Homes for the Aged. Anthropology. Cultural. Quality of Life. Social Behavior.

Qualitative Research.

\section{INTRODUÇÃO}

Apesar dos avanços recentes nos campos da Geriatria e Gerontologia e da Alimentação e Nutrição no Brasil, ainda são raros os estudos qualitativos situados no encontro dessas áreas. Em se tratando de investigar idosos institucionalizados, as poucas pesquisas brasileiras realizadas tiveram como objetivo traçar perfis epidemiológicos nutricionais. Entretanto, é igualmente importante entender a alimentação como atividade repleta de significações.

A Sociologia e a Antropologia permitem esse aprofundamento, buscando a compreensão e interpretação dos fenômenos, que vão além da busca por explicações probabilísticas. ${ }^{1}$ Entendem que, ao se alimentar, o homem cria práticas e atribui significados àquilo que está incorporando a si mesmo, o que vai além da utilização dos alimentos pelo organismo. ${ }^{2}$

Este trabalho teve como objetivo compreender o papel desempenhado pela rotina alimentar na vida dos idosos residentes em instituições de longa permanência, tendo como referencial metodológico Malinowski. ${ }^{3}$ Esse autor estudou a vida da população trobriandesa, na região de Nova Guiné. Fez suas observações pessoais e analisou diretamente as declarações feitas por eles. Compilou dados referentes à vida social, religiosa e econômica. Seu método leva em conta a complexidade da natureza humana.

Nesse contexto, descreveu a importância de se tentar de captar as impressões do investigador, os códigos internos, os padrões esperados de comportamento, os fenômenos imponderáveis da vida real, a totalidade integrada de significados, a distribuição social das funções e a organização social desta comunidade.

Utilizamos o conceito de instituição total de Goffman, ${ }^{4}$ para quem "[...] a instituição total é um local de residência e trabalho onde indivíduos com situação semelhante, separados da sociedade mais ampla por considerável período de tempo, levam uma vida fechada e formalmente administrada”. (p.11)

Essas pessoas são submetidas a normas rígidas, de forma similar ao que ocorre em qualquer instituição total, como em um convento ou prisão. Entretanto, nas palavras de Freire Júnior \& Tavares 5 “[...] o idoso se apresenta como sujeito histórico, influenciado e modificado por sua história de vida, experiências, cultura, entre outros fatores [...] Que pensar então do arranjo institucional, no qual os internos se submetem a um estilo de vida em que as prevalências coletivas se sobressaem ao individualismo?” (p.3)

Segundo Veras, ${ }^{6}$ este modelo se caracteriza por retirar os indivíduos do convívio com a sociedade, estigmatizando-os como doentes.

Mesmo diante da tendência atual em se denominar estes locais de Instituição de Longa Permanência para Idosos (ILPI), ao longo do texto podemos denominar abrigos a essas instituições, pela carga simbólica que ela preserva de instituição de custódia que abriga velhos desamparados. ${ }^{7}$ Palavra carregada de significados que está bem mais coadunada ao escopo deste estudo que as siglas técnicas cada vez mais em uso pela ciência marcada pela racionalidade moderna. ${ }^{8}$ 
Nossa observação foi exercitada através da participação em diferentes momentos da rotina destes idosos, com a indagação, a escuta e o registro dos aspectos de suas memórias Senti" profundamente o que foi descrito por Bosi: ${ }^{9}$ "Muitas passagens não foram registradas, foram contadas em confiança, como confidências. Continuando a escutar ouviríamos outro tanto e tanto mais. Lembrança puxa lembrança e seria preciso ser um escutador infinito". (p. 39)

Esta pesquisa foi aprovada pelo Comitê de Ética em Pesquisa do Hospital Universitário Pedro Ernesto (UERJ) em 2007. Foram obedecidas as orientações contidas na Resolução n ${ }^{\circ}$ 196/96 do Ministério da Saúde. Após a leitura e assinatura do Termo de Consentimento Livre e Esclarecido, os participantes foram informados dos objetivos da pesquisa, adotando-se nomes fictícios.

Realizamos o estudo em dois abrigos de idosos, um exclusivamente de mulheres e o outro, onde também moravam homens. Eles estão localizados no município do Rio de Janeiro. Foram entrevistadas dez pessoas (oito mulheres $\mathrm{e}$ dois homens), com idades variando de 66 a 93 anos. Utilizamos as técnicas de observação participante e entrevista semiestruturada.

Entendemos como entrevista semiestruturada a sequência de questões estruturadas pelo pesquisador, para explorar as estruturas de relevância dos entrevistados, enquanto a observação participante é um processo pelo qual se mantém a presença do observador na situação social específica. ${ }^{10}$

Como o critério para a definição dos sujeitos a serem entrevistados não é numérica, a suficiência foi considerada quando houve reincidência das informações. ${ }^{11}$

\section{Os abrigos}

Antes de chegar ao refeitório, observo a entrada do abrigo e revivo as mesmas sensações que sentia quando trabalhava aqui. Estaciono o carro no mesmo local, sinto o mesmo odor vindo dos quartos, não muito agradável; se tivesse que descrevê-lo, seria algo como "cheiro de úmido". Sinto uma temperatura fria, o muro de concreto que vai até bem alto. Uma brisa leve dando uma sensação de nostalgia, uma mistura de sentimentos do que foi vivido.

Uma das primeiras características que percebemos ao entrar em um abrigo é que o cotidiano possui um ritmo mais lento, onde precisamos desacelerar, porque somos acostumados ao tempo atual em que tudo é urgente. Os idosos encontram-se parados, em silêncio, ou andando a passos lentos.

Conforme observado no momento do almoço da instituição que abrigava homens e mulheres, os idosos pegavam suas bandejas e seguiam para as mesas equilibrando a fruta, que insistia em rolar, e o copo de refresco que tentava escapar. Era uma distribuição mecânica, de acordo com a sequência das preparações, com no máximo, alguns pedidos particulares: "com mais isso" ou "sem aquilo" ou "com menos isso".

Para a realização do trabalho de campo, segundo Malinowski, ${ }^{3}$ primeiramente é necessário que haja uma aculturação do observador, para que seja possível a apreensão da "totalidade integrada" de significados que precede e permite a análise da realidade cultural em questão. Malinowski ${ }^{3}$ aponta a importância de descrevermos nossas impressões enquanto investigador. Dessa forma, entendemos a importância dos detalhes para a realização de uma síntese dos indícios importantes para construir o esquema da instituição.

De acordo com Debert, ${ }^{12}$ as mulheres que vivem em abrigos mostram que a admissão nesses locais foi seguida de sofrimento e de um esforço de autoconvencimento que as levou à adaptação, e que mais tarde, ao se tornar seu lugar definitivo, sentem-se seguras, mesmo quando criticam as

\footnotetext{
Em determinados momentos o texto se encontra na primeira pessoa do singular (eu, Renata Borba de Amorim Oliveira), quando se trata de um relato extremamente pessoal, como uma sensação, emoções que são próprios de cada um e certamente diferentes de outra pessoa que estivesse na mesma cena. Já na maioria dos trechos do texto, é utilizada a primeira pessoa do plural (nós), por ter sido uma análise conjunta com os demais autores.
} 
práticas locais. E que mesmo diante de pessoas com características tão heterogêneas, ${ }^{7}$ a partir do seu ingresso, essa população se torna homogênea, caracterizando uma nova identidade social.

É possível vivenciar nos abrigos o congelamento que a instituição provoca e ao mesmo tempo, "uma liberação da sociedade", porque estas pessoas simplesmente habitam, se encontram livres de planos, havendo uma saída do "eu", um esvaziamento do investimento na construção de significados e interesses. ${ }^{13}$

Nas entrevistas, notamos como a alimentação é indissociável da vida deles, evidenciado por outras questões que vieram à tona nas conversas, como por exemplo, o abandono por parte dos filhos e as perdas familiares. Falar de comida nos remete a outros constructos simbólicos. Segundo Woortmann, ${ }^{14}$ a comida alimenta identidades, reconstrói necessidades sociais.

Os aspectos simbólicos da alimentação têm uma forte matriz afetiva por ter sua origem no universo doméstico, no convívio familiar e muito vinculada à figura da mãe e da mulher. Antigamente, a alimentação era principalmente compartilhada nos lares. ${ }^{15}$

Podemos perceber que esses idosos, principalmente as mulheres, perderam o direito de fazer da comida uma forma de expressão de identidade. Notamos que elas carregam silenciosamente lembranças dos papeis que lhes foram atribuídos ao longo de toda a vida, entre eles, o de serem as protagonistas, as responsáveis pela alimentação familiar. ${ }^{16}$

Ao entendermos que a alimentação delimita um conjunto de expressões de sentidos e significados que configuram uma espécie de linguagem dentro de um universo simbólico, ${ }^{1} \mathrm{a}$ imposição de práticas alimentares pelo abrigo promove um esvaziamento pessoal.

As escolhas alimentares faziam parte de um exercício de autonomia que realizaram para si e para sua família. É evidente a tristeza que eles sentem com essa enorme perda. S. Alberto traz na lembrança:
"Ah, eu faço um tornedor [...] de filé mignon [...] primeiro en deixo ele de molho no vinho branco de um dia pro outro [...] eu boto ele para assar [...] fazia aquilo com molho de tomate, coloca o tornedor naquele molho [...] meu macarrão sempre foi al dente, adoro albo e óleo [...] adoro comida portuguesa, rocambole de bacalhau.."

O hábito de comer constitui uma linguagem que "fala" de outras coisas como gênero, família, religião e identidade. Ou seja, a comensalidade é um meio de traçar distinções sociais. ${ }^{17}$ Os idosos levantam muitas outras questões quando $o$ assunto é alimentação, conforme o relato abaixo:

"O café daqui continua aquela água... não tem gosto, sabor, aroma, paladar, nada [...]. O Brasil tá avançando aí com um cara sem educação, tá avançando com um cara sem cultura, é sinal de que os outros são muito ruins mesmo [...] o meu problema foi um choque muito grande de ajuste, eu tava acostumado a ter a minha vida própria, tinha minha televisão, tinha men som, enfim, eu tinha uma vida regular [...] e de uma hora pra outra, você se vê sem nada." (S. Alberto)

Lima $^{18}$ também observou que a comida desempenha um papel extremamente importante na vida desses idosos, em estudo desenvolvido em abrigo: "Idosos que vagam, sentam sempre nos mesmos lugares todos os dias, localizam-se no tempo através dos horários das refeições. Que só participam de atividades se forem gratificados com comida. Que nunca saem de seus quartos, repetem o mesmo discurso, reclamam, se lamentam, choram e pedem para morrer”. (p. 3)

Entendemos que, ao experimentar alimentos e preparações, ressignificamos e recriamos a própria dinâmica cultural, ${ }^{16}$ porém, no interior $\mathrm{da}$ instituição, os alimentos e as preparações são sempre os mesmos. Os legumes e verduras são cozidos da mesma maneira, as carnes são as que oferecem "menor risco" e os acompanhamentos não variam. Exemplo disso é o de uma idosa que gosta de couve "rasgada" e no abrigo, ela é preparada "cortada". Essa diferença faz com que ela não coma couve, o que causa uma sensação de frustração.

Além disso, nas instituições estudadas, os idosos só podem comer o que é disponibilizado 
pelas mãos das autoridades locais, sem qualquer possibilidade de escolha, tipo de preparação, hora da refeição por parte dos abrigados. E o que vem de fora é rigorosamente controlado.

Dessa forma, como os idosos são obrigados a comer o que lhes é oferecido, seus hábitos alimentares se reconstroem, mas sem evolução, ${ }^{19}$ pois essa dinâmica não parte das suas escolhas. Os sabores do passado vão sendo gradativamente esquecidos. Segundo Menezes et al. ${ }^{20}$ torna-se difícil manter na comida todo o sentido especial que ela confere à existência humana em termos de significado.

Segundo Barbosa, ${ }^{21}$ não ingerimos nada aleatoriamente e todas as sociedades estabelecem normas e refeições específicas. "Os alimentos são sempre ingeridos de forma culturalizada [...] Hábitos alimentares implicam o conhecimento da comida e das atitudes em relação a ela [...] E a comida significa o que, o como, o quando, o com quem, o onde e de que maneira os alimentos selecionados por um determinado grupo humano são ingeridos." (p.92)

Ao indagarmos os idosos quanto à segurança que eles têm em relação às refeições, podemos notar desde uma admiração quanto à qualidade e quantidade dos alimentos, quanto divergência. $\mathrm{O}$ ponto de vista de D. Betina, 93 anos, há dois na instituição, faz oposição ao de S. Alberto, senhor educado que possui seu próprio dinheiro, mas relata não ter condição de morar sozinho:

"Alimentação não pode ser melhor do que é não, dona, é muito boa, é carne, é galinha, é todo tipo assim de [...] desfia a galinha, faz a carne moída, faz pirão, faz, pirê, faz almôndega, feijão, arroz, ensopado, batata [...] nãopode ser melhor [...] nãopode mesmo [...] até quando eu estava em casa, eu não comia carne $[. . .]^{\prime \prime}$

"[...] Eles cismam com a tal da alface, alface não traz nada [...]. Esquece o chuchu, que chuchu é água, esquece abóbora, abóbora é só água, não tem nada. Abóbora é muito bom com queijo ralado, doce de abóbora com queijo, com queijo não, com coco, agora, abóbora, sopa de abóbora é bom com carne seca! [...] O chuchu é com camarão? Oba! [... ]"
Assim como em Woortmann, ${ }^{17}$ observamos uma associação do que é forte com o que é sadio, que simbolicamente traz resistência para o trabalho. Na concepção deste idoso, ele ainda está apto para trabalhar, não se justificando uma comida fraca, que seria aquela direcionada para organismos velhos e doentes.

Há outro ponto forte na instituição feminina, a religiosidade. A oração é uma obrigação na rotina deste abrigo, caracterizando mais um momento de submissão do "eu".

Destacam-se as falas de D. Clara, residente há cinco anos; Jurema, mineira de 66 anos; Betina, viúva; Elaine, carioca de 83 anos e Irene, três filhos, respectivamente:

"[...] à tardinha a gente fica como a gente tá agora, vendo televisão até chegar às seis horas pra hora da prece. Ass seis horas, liga o rádio pra gente rezar, todo mundo junto. Depois da prece, janta e depois vai dormir."

"Eu gosto muito de ler, tenho uma bíblia que eu leio ela, gosto muito de ler a Bíblia, ouvir as palavras de Deus, eu sou evangélica. Tô aqui em fase de recuperação mesmo, quando eu tiver o meu cantinho, eu tenho fé que eu vou conseguir. Pra Deus nada é impossivel, né [...]"

"Escuto a minha palavra [...] Quando chega 10h, que termina a luz, a penumbra, eujá não vejo nem o Caminho do Senhor [...] Eu não como um pedaço daquele pão se não fizer minha oração [...] faço a minha oração, pedindo licença pra comer o pão, que aquele pão é sagrado"

"Já que o meu destino é este, então Jesus vai me dar saúde, e enquanto eu tiver saúde tô costurando pras crianças de Minas Gerais...”

"Ultimamente, tô fazendo tricô mais devagar, porque não enxergo dessa vista, tem época que ela fica sequinha, mas tem época que eu faço assim, minha filha, e a lágrima cai [...] no momento, esses dias, ela tá sequinha [...] agora essa, eu não enxergo dessa, mas graças a Deus, en enxergo muito dessa."

Em estudo desenvolvido por Ribeiro \& Schutz, ${ }^{22}$ a religiosidade também foi um fator 
muito marcante entre as idosas institucionalizadas, realizando, segundo o autor, a função de evitar a inutilidade total e a solidão extrema. Então teria ela o papel de alienar, de reforçar a renúncia à vida em sociedade, colocando o ser humano como objeto dos deuses? Serviria como um questionamento, ainda que velado e sutil, da rotina da instituição? A fé se coloca como esperança de saída daquele mundo de alienação para uma reinserção na vida social? Ou como forma de agradecimento por estar em uma situação melhor que a anterior?

Ainda segundo Foucault, ${ }^{23}$ no interior das instituições, há uma busca por uma perfeição místico-religiosa, numa tentativa de levar o indivíduo à "santidade", constituída por uma vida organizada em tarefas. O "exercício" é a técnica para impor ao corpo certas tarefas, repetitivas, num processo de sujeição interminável. ${ }^{24}$

Diversos autores clássicos fazem críticas à religião, como Freud, Nietzsche e Spinoza, afirmando que a religião consola os homens, mas o faz ao preço de renegar a existência e a vida. $\mathrm{E}$ o reconforto proporcionado pelo sentimento religioso não resolve as causas afetivas..$^{25}$ Segundo este autor, a religião assume a característica de uma solução mágica. E é nesse sentido que o sentimento religioso pode ser uma maneira de se colocar fora de si e da situação na qual estamos inseridos.

\section{Os idosos}

Ao chegar ao primeiro abrigo, tive a sensação de que as idosas eram bem cuidadas, mas o silêncio e a ociosidade se revelavam assustadoramente. Apresentavam um olhar triste, a maioria delas estava calada. $\mathrm{O}$ ambiente também era frio, apesar de estarmos em pleno fevereiro, pois não havia entrada de sol naquele local. A aparência delas era de asseio, estavam cheirosas, remetendo-nos ao imaginário da figura de uma avó. Umas eram extremamente doces, enquanto outras não quiseram me recepcionar. Para que se aventurar em mais uma relação que iria se esvaziar? Naquele ambiente, os laços afetivos são frágeis.
Já no segundo abrigo, sentei no refeitório, um pouco afastada dos idosos, mas não tanto, que permitisse a observação. Pudemos notar uma senhora cadeirante que acabara de comer, tendo permanecido com seu prato na mão, esperando que alguém que estivesse passando e levando seu próprio prato, pudesse levar o dela. Poucos chegaram a olhar para ela. Somente minutos depois, um senhor a empurra, retornando ao pavilhão.

Conforme pude observar no abrigo de mulheres, antes de o lanche ser servido, todas as idosas iam aos poucos se sentando perto da mesa. Poucas conversavam ou prestavam atenção na televisão que está ligada em frente à mesa.

O lanche aconteceu de forma muito rápida. A cuidadora trouxe uma bandeja plástica opaca com copos plásticos coloridos e cada uma pegava um, tomava de uma vez e devolvia. Depois, elas ficavam na mesma posição, em que nada se modificava, provavelmente aguardando a sopa do jantar, preparação que se repetia diariamente.

Essas observações foram realizadas de acordo com o sugerido por Malinowski, ${ }^{3} \mathrm{em}$ que devemos observar atentamente os sujeitos. O sentimento deles à primeira vista, o que eles faziam no momento da nossa chegada, seu comportamento, como foi a abordagem, sua atitude, modos, aparência física, gestos, rituais, regras específicas, expressões, tabus, revelações, crenças, fenômenos, comentários, idéias, informações, histórias, enfrentamentos, costumes, enfim, toda a atmosfera que envolve os idosos.

Esses fenômenos são denominados de “imponderáveis da vida real”, quais sejam, o trabalho diário, os cuidados corporais (inclusive o modo como se alimentavam), o tom das conversas, a existência de hostilidade ou laços de amizade, existência de vaidade ou ambição e como tudo isso se reflete no comportamento dos indivíduos. A observação desses elementos facilita a aproximação de uma totalidade integrada de significados.

Abordaremos alguns aspectos marcantes que foram observados, na forma de categorias, em analogia às observações realizadas por Malinowski ${ }^{3}$ na organização tribal que estudou. 
Lideranças

Para Bourdieu, ${ }^{26}$ "o gosto alimentar constituise o mais resistente e duradouro componente do babitus" e, consequentemente, o mais difícil de modificar. Ao admitirmos que em um abrigo haja a imposição de práticas alimentares diante da uniformização da rotina alimentar, entendemos que isto envolve um aprendizado de alta complexidade. ${ }^{27}$

A rigidez da rotina institucional é um fator marcante na admissão, através da delimitação de atividades, impondo-lhes códigos internos, padronizando e fixando horários, numa outra lógica de tempo. ${ }^{13}$ Conforme relato de uma residente, D. Jurema, mineira de 66 anos:

"Aqui eu levanto de manbã, tomo meu banho, depois meu café da manhã. Acordo seis horas, tem que acordar seis horas pra tomar banho, depois é o café, às oito. Depois o almoço começa assim umas onze e meia por aí, depois do almogo a gente vai pro descanso. Entre o café da manhã e o almoço eu costumo ler [...]. Depois do almoço eu venho cá pra baixo, às vezes fico sem fazer nada mesmo, ou então eu começo a ler outra coisa, pra passar o tempo e não pensar na vida, né? [...] Depois tem o lanche das três e lápras sete horas tem o jantar $[. .$.$] "$

Um exemplo de padrão esperado de comportamento na instituição é a aceitação da alimentação fornecida pelo abrigo, sem possibilidade de recusa. De acordo com Beth, cuidadora da instituição:

$$
\begin{aligned}
& \text { "Uma vovó voltou pra família [...]. Ela fazia um } \\
& \text { tipo de pirracinha. A princípio ela aceitou porque } \\
& \text { acho que colocaram na cabecinha dela que ela ia ficar } \\
& \text { por tanto tempo, depois foi se estourando, deixou de } \\
& \text { comer. A gente não pode ficar com uma pessoa que } \\
& \text { não abre a bocapra nada, ingerir comida [...]" }
\end{aligned}
$$

Se numa comunidade como a que Malinowski ${ }^{3}$ estudou, de caráter livre, a uniformidade de comportamento já é amplamente observada, em se tratando de uma instituição fechada, pode-se mais fortemente observar estas características, em razão da padronização de condutas, predispondo uma organização social extremamente rígida e esvaziadora do eu.
O poder disciplinar age através da sanção normalizadora, que é o caráter da disciplina analisado por Foucault, que mostra como as instituições impõem as regras a todos que delas se afastam. Ela é descrita assim porque faz funcionar a disciplina através do estabelecimento da norma, por meio da comparação, da diferenciação, da hierarquização, da homogeneização e da exclusão. ${ }^{28}$

Não há lideranças facilmente identificáveis, as regras são rígidas e as pessoas, submissas, o que exprime total controle. Não há vida política porque não há interesse coletivo organizado. Há pequenos resquícios de interesses pessoais, escondidos no fundo das gavetas dos armários.

Poder e acúmulo de riqueza

Ao contrário do que Malinowski ${ }^{3}$ observou, aqui não há linha de ambição social. Trata-se de um local onde há pouca ou nenhuma perspectiva em relação à valorização de papeis ou mudança de função. Isto pode ser exemplificado através da fala de D. Betina, viúva:

"[...] quem pode ficar vendo novela, fica, mas se não pode, como eu não gosto, não é não gostar, adorava uma novela, mas eu não posso tomar a frente dos outros. Aquela cadeira que eu tava sentada lá na frente é de uma menina dessas, a gente não pode tomar o lugar né [...] tá tudo tão organizado, né [...] então, eu não vejo [...]."

Pudemos observar casos em que alguns idosos apreciam o acúmulo de alimentos. Os alimentos armazenados em suas pequenas gavetas ou armários podem ser entendidos como forma de se preservar algum fio de autonomia. Este fato foi observado no momento do almoço dos idosos. Pude ver um senhor retirar da bolsa plástica uma velha vasilha de margarina e encher de comida.

Malinowski ${ }^{3}$ aponta a importância da riqueza (dada e recebida) como um dos principais instrumentos de organização social, das cerimônias, na forma de presentes e contrapresentes. $\mathrm{O}$ alimento poderia ser essa riqueza. Entretanto, como o acúmulo de alimentos é proibido nos abrigos, justificado tecnicamente 
como controle higiênico-sanitário, os indivíduos não podem contar com esse mecanismo como forma de valorização pessoal. Desta forma, ignorase a expressão de exibir, repartir e doar, concorrendo para a perda da oportunidade de criar e fortalecer laços sociais.

\section{Punição e castigo}

As regras são bem rígidas e, conforme acontecem acidentes no interior das instituições, há mais e mais proibições. Segundo D. Betina:

\section{"Aqui a gente só come, bebe e dorme, minha filha [...] até a roupa da gente, a gente lavava mas uma das meninas parece que desmaiou lá no tanque, machucou aqui, ficou com isso aqui tudo roxo [...] ninguém passa daquela porta pra fora que elas não deixam [...] tudo é elas que fazem, aqui ninguém faz nada."}

As regras da instituição não podem ser descumpridas e, para isso, os idosos são castigados com a exclusão de atividades ou negação de possibilidades, de forma que não lhes é permitido fazer nada fora da rotina.

A idosa não pode mais lavar sua toalhinha de mão porque já sofreu uma queda na área do tanque. Já não há mais peixe no cardápio porque já houve engasgo com a espinha. As idosas não participam do almoço aos domingos que é aberto à comunidade porque tem um lance de escadas e pode haver algum acidente. $\mathrm{O}$ cachorro-quente permitido é somente o de soja porque assim lhes é “recomendado". É eliminado todo e qualquer tipo de "risco". Entretanto, nenhuma vida é real se for isenta de riscos. São, dessa forma, vidas sem vida.

\section{Regras bem definidas}

As comidas são impostas, os horários delimitados, as quantidades de comida são controladas e é eliminado qualquer fator surpresa à vida desses idosos. A cuidadora da instituição, Beth, comenta:

"De vez em quando o pessoal telefona Vou fazer um lanche com as vovós', tudo na dieta delas, entendeu? Nada assim de coisa confeitada, fritura [...] Quando telefonam, jápassam logo pra mim, que aí eu já faço a lista, fica melhorpra mim. Quando eles trazem, eu achando que a vovó não pode comer aquilo, não vai comer [...]. Quando as pessoas chegam, elas ficam sentadas na mesa, aí eu digo "Quem vai servir as vovós son en [...]". Teve uma pessoa que trouxe, trouxe fora de hora, o lanche delas é às 15, eu não admito trazer lanche pra elas 15:30 [...]”

Os idosos seguem uma rotina que não permite novidades. É impressionante observar que, talvez por essa razão, eles não possuem um sentimento de pertencimento àquele lugar, mesmo após anos de moradia no abrigo.

\section{Relações entre os idosos e com o exterior}

Nesses locais, o silêncio esvaziado é notório e as pessoas evitam o contato, talvez por pensar que isso pode gerar desentendimentos. Como pudemos observar, é interessante não discutir com a idosa que tem a "regalia" de ocupar a posição da frente da televisão e a que tem uma mesa só para ela para fazer o seu tricô.

O contato que existe entre os idosos é com algum familiar, voluntários ou com pessoas que realizam visitas de "caridade". Segundo D. Jurema, contando sobre visitas eventuais que recebe:

"[...] nesses momentos eu me sinto bem, fico alegre, eu tenho uma amiga [...] ela diz. "Quando você sair daqui e tiver sua casinha, não vou te abandonar, vou lá te visitar, saber como você tá, se tá precisando de alguma coisa [... ]"

No abrigo feminino, não há mais passeios, prática que acontecia tempos atrás. Segundo os dirigentes, há dificuldade de transporte e falta de pessoal. E na segunda instituição, há esporadicamente. Os idosos que vão gostam desses momentos, mas a maioria não é contemplada com passeios.

\section{Artes e negócios com outros grupos sociais}

A arte mais realizada pelas idosas é o tricô, pois há uma professora que vai ajudar na confecção de roupas para doar às crianças carentes. Há uma distribuição social das funcõos imposta pelo 
abrigo. A idosa não determina o que vai fazer, este papel é da instituição. Relato de D. Irene, residente há cinco anos na instituição:

'Eu faço tricô que a professora dá lãpra gente [...] Então, ela dá a lã, ela dá o número do ponto [...] e eu faço tricô, faço muita blusa pra criança [...] eu fazia assim muito ponto diferente de tricô, mas aí a professora conversou comigo e disse ' Não [...] a senhora vai fazer só esse ponto mais simples, que éprapoder fazer mais quantidade [...] E eu faço bastante, faço tricôo dia inteiro [...]."

\section{Calendário anual}

Para Malinowski, ${ }^{3}$ a importância das festas está em preparar e exibir os alimentos. Aí é que se encontra o seu centro de gravidade. Se não há qualquer relação dos idosos com esta etapa anterior à comemoração, é fácil entender por que eles não se sentem verdadeiramente parte das festas.

Segundo Barbosa, ${ }^{21}$ há uma organização da alimentação em subsistemas de refeições: semanais, de fins de semana e o ritual (datas específicas). Nos abrigos, há pouca diferença entre eles. Segundo o relato de D. Elaine, de 83 anos, viúva carioca:

'No Natal, dia 24, a gente far uma ceiazinha. Primeiro tomamos a nossa sopa [...] e depois fazemos um lanchezinho. Ai é rabanada, castanhas, passas, um bocadinho de cada coisa, né. É mais uma comemoração lembrando, porque nósjá tomamos sopa. No dia seguinte, faz bacalhau, batata, faz frango, chester, né [...]."

Até no dia de Natal, elas são obrigadas a tomar sopa no jantar. As expressões no diminutivo (ceiazinha, lanchezinho, bocadinho) evidenciam o vazio da festa natalina no abrigo.

Outra data comemorada é o aniversário dos idosos. Porém, não há comemoração individual no dia. A festa é realizada por voluntários, uma vez ao mês, reunindo os aniversariantes daquele período, onde há um bolo para todas as aniversariantes.

\section{Parentesco}

As idosas são chamadas de vovós, porém na forma de vocativos esvaziados de significado, autoridade e poder. São avós destituídas de laços intergeracionais, não têm netos, não desempenham esse valor social, não participam dos arranjos familiares, não atuam no cenário privilegiado de trocas afetivas. Por vezes, são chamadas de meninas, porém sem a avidez pela vida própria da juventude, agilidade ou as brincadeiras.

\section{CONSIDERAÇÕES FINAIS}

Percebemos o abrigo como um espaço complexo em que as atividades dos sujeitos são fortemente regidas por normas, havendo uma imposição à uniformidade de comportamento.

O mundo contemporâneo é caracterizado por constantes modificações, onde o indivíduo se vê sem fronteiras. Nada permanece igual por muito tempo, o homem cria seus próprios mundos através da multiplicidade de opções disponíveis. Dessa forma, percebemos que a vida dos idosos asilados está totalmente descontextualizada dessa perspectiva.

Sob esse aspecto, seus estados mentais ficam estereotipados, pois o ambiente social e cultural em que vivem os força a pensare a sentir de determinada maneira pré-estabelecida como "adequada”.

Uma das principais práticas que se tornam estáticas é sua rotina alimentar, onde sua identidade cultural e seus traços de individualidade tornam-se enfraquecidos. Passam a ser pessoas segmentadas, espectros de seres humanos, que vivem em verdadeiros depósitos de vidas sem vida. $\mathrm{E}$ a sobrevivência e manutenção do corpo biológico são feitas pela alimentação. A ausência de uma vida social e de realizações humanas faz com que a comida tenha um papel central na vida deles.

O controle exercido pela instituição desarma os indivíduos em termos de valorização pessoal. O abrigo é centrado no funcionamento da cozinha e a rotina desses idosos é um eterno esperar pela próxima refeição. Não há flexibilidade de horários, satisfação a pequenos desejos ou possibilidades de novos sabores. A cozinha é mais importante que as pessoas. A cozinha é rígida e inflexível e tão mais poderosa quanto mais esvaziadas são as pessoas que ali vivem. 
Tendo em vista a relevância da alimentação como expressão de identidade pessoal, o valor que a comida assume na vida desses idosos, o funcionamento da cozinha como mola-mestra para o bom andamento da instituição e os horários das refeições como verdadeiros marcos diários, a comida poderia assumir papel central nesta organização social.

\section{REFERÊNCIAS}

1. Carvalho MCVS. A construção de sentidos e significados nos estilos naturais de alimentação em grandes centros no Brasil. [projeto de pesquisa]. Rio de Janeiro: Doutorado em Saúde Coletiva, Universidade do Estado do Rio de Janeiro; 2008.

2. Maciel ME. Cultura e alimentação ou o que têm a ver os macaquinhos de Koshima com BrillatSavarin? Horizontes Antropológicos 2001dez; 7(16): $145-56$

3. Malinowski B. Os argonautas do Pacífico Ocidental. 1. ed. Coleção Os Pensadores, v. xliii. São Paulo: Abril; 1976. 434p.

4. Goffman E. Manicômios, prisões e conventos. 7. ed. São Paulo: Perspectiva; 2005. 312p.

5. Freire Júnior RC, Tavares MFL. A promoção da saúde nas instituições de longa permanência: uma reflexão sobre o processo de envelhecimento no Brasil. Revista Brasileira de Geriatria e Gerontologia 2006 abr; 9 (1): 83-92.

6. Veras R. A reestruturação do Abrigo Cristo Redentor: o macroasilo transformado em uma minicidade. PHYSIS 1997; 7(2): 85-104.

7. Groisman D. A infância do asilo: a institucionalização da velhice no Rio de Janeiro da virada do século. [dissertação]. Rio de Janeiro: Mestrado em Saúde Coletiva, Universidade do Estado do Rio de Janeiro, Instituto de Medicina Social; 1999.

8. Luz MT. Natural, racional, social: a razão médica e racionalidade científica moderna. 2 . ed. São Paulo: HUCITEC; 2004. 209p.

9. Bosi E. Memória e Sociedade: lembranças de velhos. 13. ed. São Paulo: Companhia das Letras; 2006. 484p.

10. Minayo MCS. O desafio do conhecimento: pesquisa qualitativa em saúde. 9. ed. São Paulo: Hucitec; 2006. 406p.

11. Ulin PR, Robinson ET, Tolley EE. Investigación aplicada en salud pública: Métodos cualitativos.
Nesse contexto, consideramos essencial ressignificar a alimentação no interior dos abrigos, numa verdadeira mudança de paradigma. Ela tem o poder de auxiliar nessa dinâmica de enriquecimento e estruturação dessas comunidades. $\mathrm{Um}$ resgate da comida como expressão de vida.

Publicación Científica y Técnica. Washington: OMS/OPAS; 2006. n. 614.

12. Debert GG. A reinvenção da velhice: socialização e processos de reprivatização do envelhecimento. São Paulo: EDUSP, FAPESP; 1999. $272 \mathrm{p}$.

13. Maia GF, Londero S, Henz AO. Velhice, instituição e subjetividade. Interface 2008; 12(24): 49-59.

14. Woortmann KAAW. O sentido simbólico das práticas alimentares. In: Coletânea de Palestras do $1^{\circ}$ Congresso Brasileiro de Gastronomia e Segurança Alimentar 2004, Brasília. Brasília: UNB; 2004. p. 3

15. Garcia RWD. Práticas e comportamento alimentar no meio urbano: um estudo no centro da cidade de São Paulo. Cad Saúde Pública 1997 set; 13(3): 455-67.

16. Gimenes MHSG, Morais LP. Vozes femininas, saberes culinários: o feminino e a dinâmica das identidades regionais por meio da culinária. Caderno Espaço Feminino 2008 jan./jul; 19(1):353-68.

17. Woortmann EF. Hábitos Alimentares. In: Coletânea de Palestras do $1^{\circ}$ Congresso Brasileiro de Gastronomia e Segurança Alimentar 2004, Brasília. Brasília: UNB; 2004. p. 44.

18. Lima MAXC. O fazer institucionalizado: $\mathrm{O}$ cotidiano do asilamento. [dissertação]. São Paulo: Pontifícia Universidade Católica de São Paulo, Programa deEstudos Pós-graduados em Gerontologia; 2005.

19. Oliveira SP, Thébaud-Mony A. Estudo do consumo alimentar: em busca de uma abordagem multidisciplinar. Revista de Saúde Pública 1997 abr; 31(2): 201-8.

20. Menezes MFG, et al. Alimentação saudável na experiência de idosos. Mimeo. 2009

21. Barbosa L. Feijão com arroz e arroz com feijão: o Brasil no prato dos brasileiros. Horizontes Antropológicos 2007 jul./dez; 13(28): 87-116. 
22. Ribeiro AP, Schutz GE. Reflexões sobre o envelhecimento e bem-estar de idosas institucionalizadas. Revista Brasileira de Geriatria e Gerontologia 2007; 10(2).

23. Foucault M. Vigiar e Punir: nascimento da prisão. 6. ed. Petrópolis: Vozes; 1988. 280 p.

24. Benelli SJ. A instituição total como agência de produção de subjetividade na sociedade disciplinar. Estudos de Psicologia 2004 set./dez; 2(3): 237-52.

25. Martins A. Religiões e tecnologias médicas: soluções mágicas contemporâneas. Uma análise a partir de Spinoza, Nietzsche e Winnicott. In: Barros JA, et al. Os fármacos na atualidade: antigos e novos desafios. Brasília: ANVISA; 2008. p. 87-109.

26. Bourdieu P. La distinción: criterio y bases sociales del gusto. Madrid: Taurus; 1988.597 p.

27. Santos LAS. O corpo, o comer e a comida: um estudo sobre as práticas corporais alimentares cotidianas a partir da cidade de Salvador. Salvador: EDUFBA; 2008. 330 p.

28. Portocarrero V. As ciências da vida: de Canguilhem a Foucault. Rio de Janeiro: FIOCRUZ; 2009. 259 p. 
